\title{
EFFECTS OF BETAHISTINE ON THE BINDING OF NICOTINE TO NICOTINIC CHOLINERGIC RECEPTORS IN RAT BRAIN SYNAPTOSOMES
}

\author{
Kazuhide YOSHIDA, Yuzuru KATO and Hiroo IMURA \\ The Second Department of Interna! Medicine, Faculty of Medicine. \\ Kyotu University, Sakyo-ku, Kyoto 606. Japan
}

Accepted June 3, 1981

Betahistine is effective in the treatment of labyrinthine vertigo (1). It has been reported also that betahistine improves mental function in patients with arteriosclerosis-related dementia (2-5). Although the mechanism of action of betahistine lias not been fully elucidated, it is known to have a potent cerebral and peripheral vasodilator action. the pharmacological properties of histamine (6). However, the effect of this antidinic on the cerebral blood flow is not blocked by anti-ristaminic drugs.

We previously demonstrated the existence of nicotinic cholinergic receptors in brain synaptosomes utilizing ${ }^{3} \mathrm{H}$-nicotine as a ligand (7). The binding of ${ }^{3} \mathrm{H}$-nicotine is competitively inhibited by $\mathrm{D}$-tubocurarine and carbamylcholine, but not by atropine. These receptors seem to exist in presynaptic nerve endings, since nicotine enhanced the release of noradrenaline from synaptosomes (8). Since a portion of the structure of betahistine is stereochemically similar to that of nicotine. we studied the effect of betahistine on the binding of ${ }^{3} \mathrm{H}$-nicotine to brain nicotinic receptors.

Male Wistar rats weighing approximately $200 \mathrm{~g}$ were used. Subcellular fractionation was done by the conventional techriques of Gray and Whittaker (9), and the synaptosomal fraction was further washed by a slight modification of the method of Bradford et al. (10). Briefly, $10 \%$ (W/V) homogenate of the brain excluding the corcbollum in $0.32 \mathrm{M}$ sucrose was contrifuged in a refrigerated centrifuge at $1,000 \times \mathrm{g}$ for $10 \mathrm{~min}$. The supernatant was then centrifuged at $17,000 \times \mathrm{g}$ for $55 \mathrm{~min}$. The resultant precipitate (P2) was further subfractionated into myelin (A). synaptosomal (B) and mitocinondrial (C) fractions by centrifugation at $75.000 \times \mathrm{g}$ for 60 min on a discontinuous sucroso gradiont. The synaptosomal pellet was obtained by further centrifugation of the diluted intermediate layer (B) of the gradient tube at $55,000 \times \mathrm{g}$ for $20 \mathrm{~min}$ in $0.45 \mathrm{M}$ sucrose, and the synaptosomal supernatant including microsomes and myelin fragment was discarded.

Synaptosomes obtained in the form of a pellet were resuspended in $50 \mathrm{mM}$ Tris $-\mathrm{HCl}$ buffer $(\mathrm{pH} 7.7)$ to give a concentration of $170 \mathrm{~kg}$ protein/ $\mathrm{ml}$. To determine the binding of ${ }^{3} \mathrm{H}$-nicotine to synaptosomes, a $0.5 \mathrm{ml}$ aliguot of this suspension was incuoated with $0.5 \mathrm{ml}$ of Tris- $\mathrm{HCl}$ buffer containing 3 pmol of ${ }^{3} \mathrm{H}$-nicotine (S.A. $25.0 \mathrm{ci} / \mathrm{mmol}$. $\left(\mathrm{G}-{ }^{3} \mathrm{H}\right)$-nicotine-D-bitartrate, Radiochemical Centre. Amersham) with or without increasing quantities of cold nicotine, betahistine or related substances, at $25^{\circ} \mathrm{C}$ for $30 \mathrm{~min}$, as described previously (7). Then, the reaction mixture was filtered (Whatman GF/B) to remove the unbound fraction and the preparation washed with Tris-HCl buffer. The radioactivity retained on the filter paper was counted in $10 \mathrm{ml}$ of toluene scintillation cocktail using a Packard Tri-Carb scintillation 


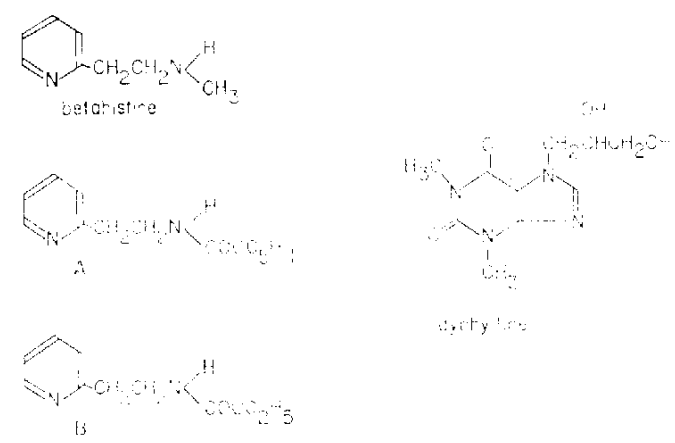

Fig. 1. Structural formulao of the diugs examined.

spectrometer. Protein contents of suspensions were determined by the method of Lowry et al. (11). The reported values are means of quadruplicate detcrminations.

The structural formulae of two antidinics examined, betahistine and dyphylline are shown in Fig. 1 which includes two other betahistine derivatives, $A$ and $B$. All these drugs are synthesized and provided by Eisai Co., Ltd., Tokyo.

The binding of ${ }^{3} \mathrm{H}$-nicotime to synaptosomes was displaced by the addition of cold nicotine. Cold nicotine at $10^{-5} \mathrm{M}$ inhibited $3 \mathrm{H}$-nicotino binding by $90 \%$. The remaining $10 \%$ was regarded as non-specific binding.

The specific binding of ${ }^{3} \mathrm{H}$-nicotine to synaptosomes was reduced by botahistine as shown in Fig. 2. Belahistine inhibited 50\% of ${ }^{3} \mathrm{H}$-nicotine specific binding at the concentration of $7 \times 10^{-8} \mathrm{M}$, but at the concentration below $10^{-6} \mathrm{M}$, dyphylline or two betahistine derivatives had little effect on the nicotine binding. The addition of 100 $\mathrm{mM}$ sodium reduced nicotinic binding by about 50\%. Furthermore, with the addition of $100 \mathrm{mM} \mathrm{NaCl}$, betahistine inhibited half of the ${ }^{3} \mathrm{H}$-nicotine specific binding at the concentration of $2 \times 10^{-7} \mathrm{M}$. From the double-reciprocal plot, ${ }^{3} \mathrm{H}$-nicotine specific binding was reduced in the presence of betahistine competitively, but it was inhibited

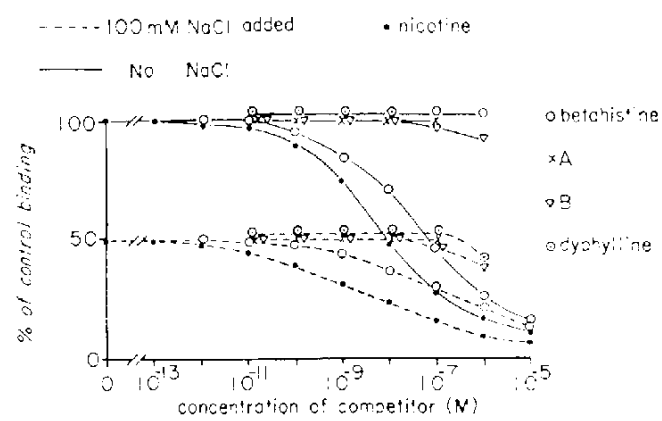

Fig. 2. Inhibition of ${ }^{3} \mathrm{H}$-nicotine binding to synaptosomes by betahistine and other related açents. The effect of sodium chloride on ${ }^{3} \mathrm{H}$-nicotine binding is shown by ......... Data, expressed as a percent of the control ${ }^{3} \mathrm{H}$ nicotine total binding to synaptosomes are plotted on the ordinate against the drug concentration ( $\log M)$ on the abscissa. ${ }^{3} \mathrm{H}$-nicotire specific binding is regarded as the birding in the absence of cold nicotine minus the binding iil the presence of $10^{-5} \mathrm{M}$ cold nicotine.

by $100 \mathrm{mM} \mathrm{NaCl}$ in a non-competitive fashion.

The present study demonstrates that betahistine inhibits the specific binding of ${ }^{3} \mathrm{H}$-nicotine to synaptosomes competitively, whereas two betahistine derivatives and dyphylline have, if any, little effect. The present study also shows that $100 \mathrm{mM}$ sodium chloride inhibits the specific binding of ${ }^{3} \mathrm{H}$-nicotine to synaptosomes by about $50 \%$, indicating that a kind of 'sodium effect' exists in the binding of nicotinic agonists to their receptors. The fact that sodium reduces ${ }^{3} \mathrm{H}$-nicotine specific binding non-competitively suggests that this compound may alter the configuration of nicotinic cholinergic receptors.

It is concluded that betahistine may play a pharmacological role via nicotinic cholinergic receptors in the brain.

Acknowledgements: We thank Eisai Co. Ltd. Tokyo, Japan, for the supply of betahistine and its related agents and $\mathrm{Mr}$. Kenn Johannessen for secretarial assistance. 


\section{REFERENCES}

1) Hood, N.A.: Diseases of the central norvous system, cerebral atherosclerosis, transient ischaemic attacks, Menicre's disease and disorders of balance. Brit. med. J. 4, 398-400 (1975)

2) Esser, A.H. and Reis, J.: Preliminary study of betahistine in chronic psychiatric patients with symptoms of arteriosciorosis corcbri. Curr. Therap. Res. 10, 122-127 (1968)

3) Meyer, J.S., Mathew, N.T., Hartmann, A. and Rivera, V.M.: Ora'ly acministered batahistice and regional cerobral blood flow in corebrovascular disease. J. Clin. Pharmacol. 14, 280$289(1974)$

4) Seipel, J.H., Fisher, R. Floam, I.E. and Bohm, M.: Rheoencephalographic and other studies of betahistine in rumans: II. The cerebral and oeripheral microcirculatory effects of single doses in geriatric patients with "pure" arteriosclerotic dementia. J. Clin. Pharmacol. 15 , 155-162(1975)

5) Seipel, J.H., Fisher, R., Blatchley, R.J., Floam, J.E. and Bohm, M.: Rheoencephalographic and other studies of betahistine in human: IV. Prolonged administration with improvement in arteriosclerotic dementia. J. Clin. Pharmacol. 17. 140-161 (1971)

6) Anderson, W.D. and Kubicek, W.G.: Effects of betahistine $\mathrm{HCl}$, nicotiric acid and histamine on basilar blood flow in anesthetized dogs. Stroke 2, 409-415 (1971)

7) Yoshida, K. and Imura, H.: Nicotinic cholinergic recoptors in brain synaptosomes. Brain Res. 172, 453-459(1979)

8) Yoshida, K., Kato, Y. and Imura, H.: Nicotineinduced release of noradrenaline from hypothalamic synaptosomes. Brain Res. 182, 361$368(1980)$

9) Gray, E.G. and Whittaker, V.P.: The isolation of nerve endings from brain: an electromicroscopic study cf cell fragments derived by homogenization and centrifugation. J. Anat. 96, 79-96 (1962)

10) Bradford, H.F., Bennett, G.W. and Thomas, A.J.: Depolarizing stimuli and the roloase of physiologically active amino acids from suspensions of mammalian synaptosomes. J. Veurochem. 21, 495-505 (i.973)

11) Lowry, O.H., Rosebrough, N.J., Farr, A.L. and Randal!, R.J.: Protoin measurement with the Folin phencl reagent. J. Biol. Chem. 193, $265-275(1951)$ 